\title{
GLACIAL ABRASION AND SLIDING: THEIR DEPENDENCE ON THE DEBRIS CONCENTRATION IN
}

\author{
BASAL ICE
}

\author{
by \\ Bernard Hallet \\ (Quaternary Research Center and Department of Geological Sciences, University of \\ Washington, Seattle, Washington 98195, U.S.A.)
}

\begin{abstract}
A model of bedrock abrasion by a temperate glacier is developed that takes into account the significant impeding effect of scattered rock fragments at the ice-rock interface on glacier sliding. An increase in the debris concentration above a relatively low value can reduce the abrasion rate by decreasing both the flux of rock fragments and the effective forces which press fragments against the bed. Abrasion of a simple wavy bed is shown to be most rapid for a relatively low debris concentration above which the abrasion varies inversely with the debris content. A similar concentration dependence of abrasion is expected for beds of arbitrary geometry but low roughness. Sliding glaciers will tend to abrade until the basal ice is nearly stagnant at which point rocks of all sizes start to Todge against the bed.
\end{abstract}

\section{INTRODUCTION}

In addition to improving our understanding of glacial erosion, theoretical considerations of glacial abrasion can provide a basis for analysing the probable effects of debris in the ice on the sliding and, hence, on the motion of temperate glaciers. In this paper, earlier work on abrasion by temperate glaciers with scattered debris (Hallet 1979) is extended to include explicitly the important effect of debris at the glacier bed on rates of glacier sliding. Before exploring this model, it is instructive to view some of the previous and sometimes conflicting developments in this field.

\section{PREVIOUS WORK}

One of the clearest and earliest discussions of glacial abrasion processes was presented by G.K. Gilbert (1910), who recognized that abrasion depends on the speed of the basal ice, the pressure exerted by rock fragments on the bed, the shape of the bed, the quantity of rock debris in the basal ice, and the hardness of striating rock fragments. In his work on crescentic gouges, Gilbert (1906: 307-309) clearly perceived that a rock fragment can fracture or striate the glacier bed only when the stresses at points of contact between the glacier bed and rock fragments are considerably greater than those on immediately adjacent areas. He referred to this necessary stress difference as "differential pressure"; the corresponding contact force will be termed "effective contact force" in this paper. More- over, Gilbert (1906:313) suggested that the differential pressure resulted from the flow of ice toward the bed, due to local ice deformation around bed obstacles, and was dependent on the speed of the basal ice and on its high "resistance to flowage". It is worth emphasizing that the mean pressure at the glacier-rock interface does not figure in the effective contact force, which controls the abrasion process. This critical notion stems from the reasonable assumption that, where abrasion is likely to be most important, such as along rock surfaces facing up-glacier, ice would be in close contact with the bed and scattered rock fragments at the bed would be effectively surrounded by ice. A water film of micron thickness would probably exist between ice and rock. It follows that pressures in the ice or vater would contribute equally to the pressure at the points of contact and to the pressures on the rest of the bed, thereby leaving the pressure difference unchanged.

As part of a comprehensive study on the dynamics of cirque glaciers, McCall (1960) considered the abrasion process briefly, treating ice as a perfectly plastic material. He concluded that the effective contact stress between rock fragments and the glacier bed was essentially independent of glacier thickness. According to the plasticity model, the contact stress was constrained by the yield strength of the ice. In the context of mare modern views of glacier sliding, Röthl isbercer (1968) examined how factors controlling abrasion rates might ultimately affect the formation of largescale glacier landforms. He showed that basal melting and ice deformation were critical to the abrasion process because they control the supply of debris necessary to abrade the bed. Moreover, he clearly recognized that rock fragments are effectively floating in the ice, and he derived relationships characterizing the tendency of fragments to be forced against the bed by the motion of ice toward the bed.

In 1974, Boulton reported interesting new measurements and produced the first theoretical calculations of rates of glacial abrasion. In contrast to all other work on abrasion, Boulton's model is based on the assumption that the relevant contact stress between rock fragments and the glacier bed depends on the mean pressure in the basal ice. Current views of glacier sliding over bedrock surfaces (in which ice is regarded as an ideal fluid) contradict this assumption, because scattered rock fragments contacting the bed would tend to be effectively surrounded 
by ice, particularly along stoss surfaces where abrasion is most important. In defense of his problematic assumption, Boulton (1974) points out that individual striating rocks are not invariably surrounded by ice or water because rocks have of ten been observed between the glacier sole and the bed. However, such observations can generally be made only in subglacial cavities down-glacier of bed bumps. These cavities exist because the ice slides faster than it sags, and it does not necessarily press on fragments at the glacier-rock interface. It follows that in such cavities the fragmentbed contact forces may have little or no relation to the stress field in the basal ice. Boulton's results (1974) should therefore be considered with skepticism. One of his particularly problematic predictions is that for a very thick glacier, the bed contact forces can be so high that fragments would slow down, thereby reducing abrasion rates and eventually inducing lodgement. The existence of deep valleys and fjords, perhaps the most spectacular products of glacial erosion, is a clear suggestion that this questionable prediction should be reconsidered.

Using the linear glacier sliding theory of Nye (1969) as a theoretical framework, a selfconsistent theoretical model for bedrock abrasion by temperate glaciers with scattered rock fragments entrained in the basal ice was developed (Hallet 1979). On the basis of this model, which is conceptually in accord with Gilbert's (1906, 1910) and Röthlisberger's (1968) treatments, the primary contribution to the effective contact force is a pseudo-viscous drag imparted by the flow of ice towards the bed around rock fragments due to basal melting and straining. According to this concept of the forces pressing rock fragments against the glacier bed, effective contact forces are independent of glacier thickness. Moreover, ignoring the small contribution of the buoyant weight of rock fragments, the effective contact forces would vanish for stagnant ice not melting at its base.

In the initial model (Hallet 1979), the rate of abrasion by a single rock fragment was calculated and multiplied by the areal concentration of particles at the ice-rock interface to obtain a spatially varying rate of glacial abrasion for a given sliding velocity. This model can be extended and rendered considerably more interesting by recognizing explicitly that debris at the glacier bed affects, and can even control, the rate of glacier sliding.

In the present paper, the sliding velocity is calculated as a function of both the bed roughness and the debris concentration, which is arbitrarily assumed to be uniform. Glacier ice is treated as a regelating Newtonian viscous fluid because it is analytically simple, yet illustrates the fundamental physics of glacial abrasion and sliding. The viscous drag on rock fragments at the bed is obtained by calculating the equivalent drag on a fragment in an unbound body of temperate ice and modifying it with a bed influence factor. As in the initial model, the debris content will be assumed to be low enough that the flow around any given rock fragment or bed irregularity is independent of other such flows. Quantitative considerations of the model are therefore limited to debris concentrations not exceeding approximately $10 \%$ by volume of the basal ice, but the form of the derived functional relations is likely to remain valid to considerably higher concentrations. As mentioned in the discussion section, this model appears appropriate for most temperate glaciers that are actively abrading their beds. However, a different theoretical approach would be required for abrasion by glaciers having a distinct basal debris layer. because fragments would interact strongly.

\section{GENERAL MODEL}

The average, gravitationally induced, shear stress $\tau$ at the base of a temperate glacier must be balanced by the basal drag due both to bed irregularities and to rock fragments dragged against the bed. The components can be viewed independently, as shown in Figure 1 , and can be expressed as:

$$
\tau=\xi \cap U+\mu \odot \bar{F}
$$

where $U$ is the sliding velocity, $\mu$ is the coefficient of rock-to-rock friction, $c$ is the areal concentration of rock fragments in contact with the bed, and $\bar{F}$ is the average contact force between rock fragments and the bed. The proportionality factor $\xi$ is dependent on bed

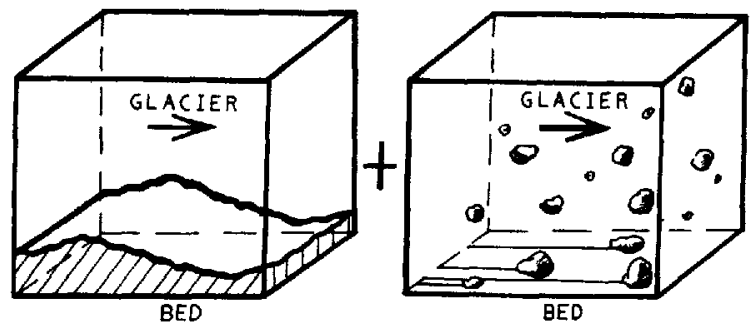

Fig.1. Schematic representation of the basal drag arising from both bed irregularities and rock fragments embedded in the ice. Unlike previous models of sliding, the drag does not necessarily vanish for perfectly smooth beds.

roughness, and $\eta_{i}$ is the effective viscosity of basal ice. For example, according to Nye (1970: 385), for a low-roughness two-dimensional bed, comprising arbitrary undulations transverse to the ice-flow direction, $\xi$ depends on the spectral power density of the bed profile. Except for the largest rock fragments, for which the buayant weight is of magnitude comparable to the viscous drag imparted by ice flow (Hallet 1979: fig.2), the effective contact force is simply proportional to the ice velocity $v_{\mathrm{p}}$ normal to the bed, which is governed by the rates of melting and of ice deformation. Neglecting this special case, the drag on a spherical particle can be expressed as (Hallet 1979:42):

$$
E=\frac{f 4 \pi n R^{3}}{R_{*}{ }^{2}+R^{2}} v_{n}
$$

where $f$ is a bed influence factor that modifies the viscous drag for an object in an infinite ice body, as initially derived by watts (unpublished), for near-bed conditions. $R_{*}$ is the transition radius analogous to the transition wavelength used in the glacial sliding problem.

In general, the ice velocity $v_{n}$ normal to the bed arises from three contributions: regelation sliding, uniform melting (due ta geothermal heating and sliding friction), and vertical straining. However, it is clear that, for most glaciers sliding over uneven beds, glacial abrasion will be largely restricted to surfaces facing up-glacier, where $v_{n}$ is essentially the melting rate due only to regelation plus the straining associated with flow over 
obstacles. Neglecting the contribution due to uniform basal melting, Nye's (1969: 454) analysis of glacier sliding can be used to show that

$$
v_{n}=k U
$$

where the factor $k$ depends on the bed geometry and varies with position along the bed. Abrasion is restricted to surfaces along which ice converges with the bed, which correspond to positive values of $v_{n}$ and, hence, of $k$. The average abrasion rate of the glacier bed depends on the average of positive values of $k$ which vill be denoted by $\vec{k}$. Negative values of $k$ correspond to ice diverging with the bed and, hence, reflect sites where frictional drag and abrasion both vanish.

It can be seen from Equations (2) and (3) that the contact force $F$ is proportional to the sliding velocity. Substitution of these expressions into Equation (1) leads to the following expression for the sliding velocity as a function of the shear stress $t$ and debris concentration $e$ :

$$
U=\frac{\tau}{n(\xi+\bar{\delta} \mu c)},
$$

where

$$
\bar{\Omega}=\frac{\bar{k} f 4 \pi R^{3}}{R_{*}^{2}+R^{2}}
$$

Here and in subsequent equations, the bars represent spatial averages of the positive values of the indicated parameter. As expected, the sliding velocity would tend to decrease with increasing debris concentration $c$. This result can be readily incorporated into Hallet's (1979) model in which the abrasion rate $\dot{A}$ is given by:

$$
\dot{A}=\alpha \odot v_{\mathrm{p}} F \quad,
$$

where the attritivity coefficient $\alpha$ is an empirical parameter dependent primarily upon hardnesses of rock fragments and bedrock and $v_{p}$ is the rate at which rock particles are moved $p$ along the bed.

For actively sliding glaciers, $v_{p}$ is nearly equal to the component of sliding velocity parallel to the bed, because the retardation due to friction is theoretically of the order of the melting rate which is relatively small for lowroughness beds (Hallet 1979: 49). Hence, if we equate $v_{p}$ and $U$, and utilize the preceding equations, this leads to:

$$
\dot{A}=\frac{\alpha c \Omega \tau^{2}}{n(\xi+\bar{\Omega}+c)^{2}}
$$

A particularly noteworthy aspect of Equation (6) is that the abrasion rate does not necessarily increase monotonically with debris concentration; in fact, for low-roughness beds, for which $\bar{\Omega} \mu c \gg \xi, \dot{A}$ varies as $c^{-1}$. The rate of abrasion will tend to be maximal for a debris concentration $c_{\max }=\xi / \bar{\Omega}_{\mu}$. This concentration is that at which the drag imparted by bed irregularities equals that imparted by debris dragging along the bed, and hence can be regarded as a transition concentration. To evaluate $c_{\max }$ as well as to calculate the effect of debris on sliding, the influence of the bed on the viscous drag caused by flow around fragments touching the bed must be evaluated explicitly and actual or idealized bed-roughness data must be used.

\section{VISCOUS DRAG ON A SPHERE CONTACTING THE} GLACIER BED

Morris (1979) demonstrated that for the problem of flow of temperate ice around an obstacle near the bed, no finite solutions could be obtained using the conventional regelation boundary conditions. Although it is not presently clear how to modify the boundary conditions properly and thus solve this problem, it is useful, as a first approximation, to consider closely analogous problems involving the creeping flow of a linear viscous fluid around a sphere that is in contact with a flat, rigid surface. These flow solutions should be very similar to those for ice flow around rock fragments sufficiently large that the motion around them is primarily due to viscous deformation. For smaller fragments, the influence of the bed, as well as fragment-shape effects, probably tends to be less. For example, in some cases involving only regelation, the drag on a fragment depends only on the volume of the specimen and not on any other dimension (Nye 1967:1261). If the drag is independent of the fragment geometry, it appears unlikely that it would depend on the geometry or proximity of an adjacent surface. The influence of the bed on the regelation siiding past fragments on the bed can, therefore, be ignored in a rough approximation similar to Lliboutry's (1979:7980).

Two analyses of creeping viscous flow are particularly helpful to evaluating the probable magnitude of wall effects for this glacier problem: (1) flow about a fixed sphere in contact with a fixed plane wall when the fluid motion in the absence of the sphere is assumed to be a uniform shear flow (0'Neill 1968); (2) normal forces experienced by a solid sphere resting on a plane wall in axisymmetric stagnation flow (Goren 1970). In Goren's problem, the fluid flow converges with a plane and diverges radially near the wall about an axis perpendicular to the plane and passing through the sphere center; the velocity along that axis is proportional to the square of the distance from the wall and vanishes at the wall. Although the glacial problem is substantially different, because the velocity normal to the bed is finite at the bed, a monotanic increase in the fluid velocity away from a plane is of interest because analogous velocity gradients result from ice extension parallel to the bed. Taking the velocity at a distance of one radius from the bed as representative of the effective velocity around a particle contacting the bed, the viscous drag on a sphere in uniform shear flow and the drag on a sphere in an axisymmetric flow were found to be 1.7 and 2.4 times higher, respectively, than the drag imparted on an isolated sphere by a flow of equivalent relative velocity in an unbound medium. The particle shape must al so be considered, particularly for fragments that are not nearly equidimensional. However, according to Happel and Brenner $(1965: 334)$ the effect does not seem very important. For example, for oblate ellipsoids, a six-fold increase in the axial ratio only modifies the viscous drag on the sphere near a wall by about $10 \%$. Hence it seems reasonable that the influence of the bed on the drag on a sphere can be included in the wall factor $f$, which will be of the order of $f_{t}=1.7$ for flow tangent to the bed and of $f_{n}=2.4$ for flow normal to the bed.

\section{ABRASION OF A SINUSOIDAL BED}

The principal elements of the physics of abrasion are well illustrated by considering abrasion of a simple sinusoidal bed with undulations perpendicular to the flow direction and 
with a range of given uniform debris concentra-

tions in basal ice.

According to Nye (1969:455), the drag due to sinusoidal bed undulations without debris is such that the bed-roughness factor is:

$$
\xi=\frac{a^{2} k^{3} k_{*}^{2}}{k_{*}^{2}+k^{2}}
$$

where $a$ and $k$ are the amplitude and wave number of the bed undulations and $k_{*}$ is the transition wave number. On the bas is of Equations (2), (3), and (4), and Nye's (1969:454) equation (32) for the velocity components of the ice at a distance $z=R$ from the bed, it can be shown that

$$
\bar{\Omega}=-\frac{2}{\pi} a k\left\{\frac{k_{*}^{2}}{k_{*}^{2}+k^{2}} \exp \{-k R\}(k R+1)-1\right\}\left\{\frac{f_{n} 4 \pi R^{3}}{R_{*}^{2}+R^{2}}\right\}
$$

With this equation, the sliding velocity and abrasian rate can be computed readily on the basis of Equations (4) and (5). The rate of abrasion of sinusoids was calculated for a range of bed roughness, bed-undulation wavelengths, fragment radii, and fragment concentrations. The particle velocity $v_{p}$ was calculated according to equation (11) of Hallet (1979:43), but could have been approximated within a few percent by the sliding velocity $u$

The calculations and diagrams are for spherical fragments of particular sizes and concentrations, expressed in terms of the proportion $P$ of the bed effectively covered by debris. The maximum possible concentration is assigned a value of unity, taken to represent close cubic packing of fragments in contact with the bed. $P$ can therefore range from 0 to 1 and is related to the debris concentration $P=4 R^{2} \mathrm{c}$. The viscosity of the ice was taken to be $3 \times 10^{12} \mathrm{~Pa} s$ and the transition parameters $R_{*}$ and $k_{*}$ were assigned representative values of $0.1 \mathrm{~m}$ and $10 \mathrm{~m}^{-1}$, respectively. The abrasion rates were calculated for the center of surfaces facing up-glacier and the bed-influence factor $f$ was taken to be 2.4. An attritivity coefficient of $3 \times 10^{-5} \mathrm{~kg} \mathrm{~J}^{-1}$ was chosen on the basis of preliminary experiments for 1 imestone abrading the same 1 imestone. This value is in accord with that expected from the theoretical relation between attritivity and the hardness and density of limestone, as graphically presented by Metcalf (1979:242). The average basal shear stress $\tau$ was taken to be $10^{5} \mathrm{~Pa}$ and melting due to geothermal heating was neglected. As 11 lustrated in Figure 2, rock debris can slow glacier sliding considerably even at relatively low concentrations. As expected, debris has the greatest effect on sliding over smooth beds for which sliding would be very rapid in the absence of debris. As bed roughness increases, it contributes a proportionally large share of the basal drag and hence sliding is decreasingly influenced by rock debris. The relation between the abrasion rate, the size of fragments, and the wavelength of bed undulations is shown in Figure 3 . For the relatively low debris concentration used in this sample $(P=0.1)$, abrasian might be expected to be fastest for fragments with $R=R_{*}=100 \mathrm{~mm}$ because they are the ones that would be pressed against the bed most forcefully if the ice was converging with the bed uniformly (with no straining). However, considerable ice deformation takes place as ice slides over bed irregularities and past fragments contacting the bed. Hence, fragments of different sizes are subjected to different effective rates of ice convergence with the bed, which are dependent on wavelength. It is noteworthy that for rock fragnents that are about equal in size or larger than the wave-

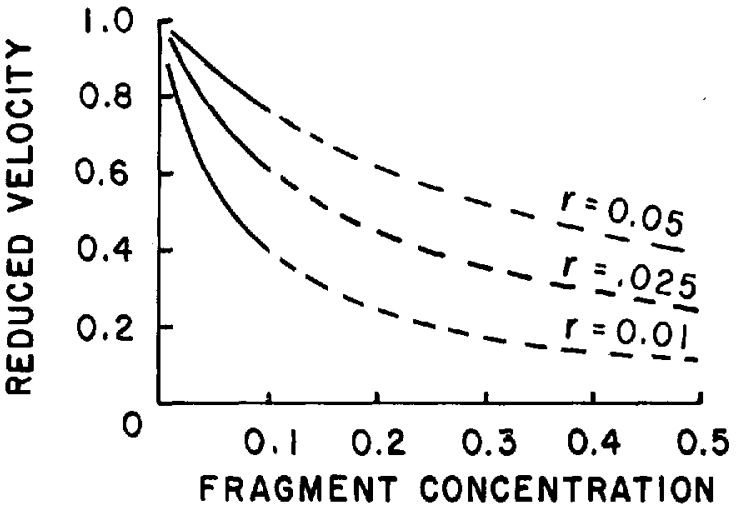

Fig.2. Reduction of the sliding rate due to debris on the bed, expressed as the calculated sliding rate affected by debris divided by that calculated for the same bed but without debris. Numerals refer to various bed-roughness values $r$ (amplitude/wavelength). Debris concentration is expressed as proportion $P$ of the bed effectively covered by debris, unity representing close cubic packing. The wavelength of bed undulations and radius of rock fragments were 1 and $0.1 \mathrm{~m}$, respectively.

length, the effective value of the ice velocity $v_{\mathrm{n}}$ normal to the bed (at $z=R$ ) approaches $a k U$. Figure 4 shows that if the bed is characterized by relatively short wavelength irregularities, abrasion is fastest for relatively low debris concentrations. The optimum debris concentration $C_{\max }$ at which abrasion is fastest is shown in Figure 5 , as calculated by setting $C_{\max }=\xi / \bar{\Omega} \mu$. In terms of the proportion $P_{\max }$ of the bed effectively covered with debris, the optimum debris content at which abrasion is fastest can be adequately evaluated as:

$$
P_{\max } \approx 2.7 \frac{r k_{\star}^{2}\left(R_{\star}{ }^{2}+R^{2}\right)}{R k}
$$

where the bed roughness $r$ is the amplitude to wavelength ratio. For wavelengths less than $2 \mathrm{~m}$ and fragment radii less than $100 \mathrm{~mm}$, abrasion is most rapid by glaciers with 10 to $30 \%$ debris (by volume) in the basal ice.

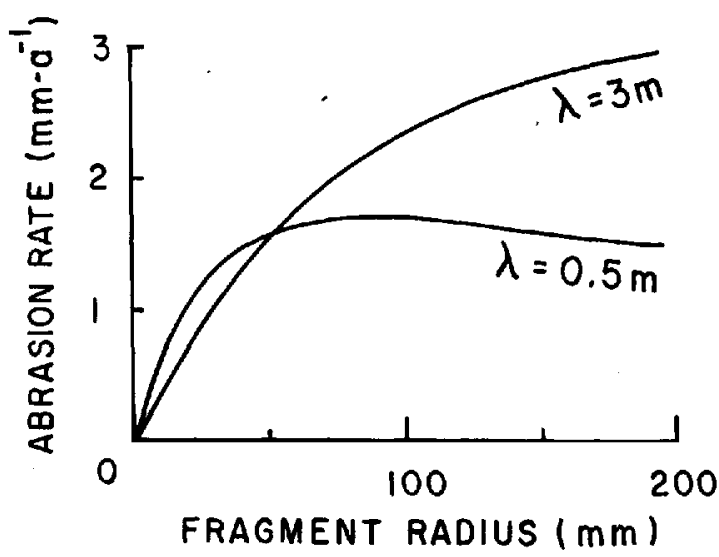

Fig.3. Abrasion rate as a function of rockfragment size and bed-undulation wavelength $\lambda$, for constant bed roughness $(r=0.05)$ and $10 \%$ of the bed being effectively covered with debris. 


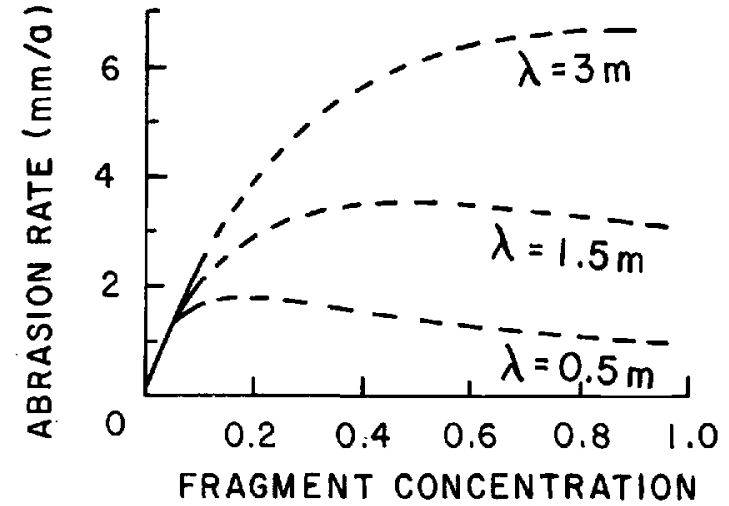

Fig.4. Rate of abrasion by fragments $200 \mathrm{~mm}$ in diameter as a function of the proportion of the bed effectively covered by debris. Bed roughness was taken to be 0.05 and three different wavelengths $\lambda$ of bed undulations were considered.
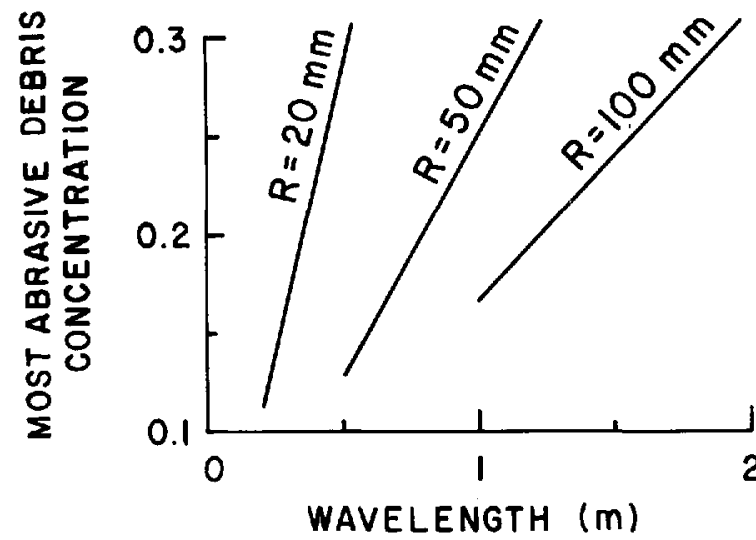

Fig.5. Dependence of the fragment concentration $P$ at which abrasion is maximal on the radius $R$ of fragments and wavelength of bed undulations with uniform roughness of 0.025 .

\section{SUMMARY AND IMPLICATIONS}

This analysis shows that the sliding rate is significantly influenced by debris at the bed even in low concentrations (Fig.2). As a result, the abrasion rate, which depends sensitively on the sliding rates, tends to decrease with increasing debris concentration above a relatively low concentration at which the drag imparted by bed irregularities equals the debris-induced drag. Therefore, abrasion is probably most rapid for glaciers containing only scattered debris at their bases (Fig.5), much as was anticipated by Röthlisberger (1968). Preliminary results of another abrasion model, treating ice as a regelating power-law fluid, suggest that at relatively high debris contents the rates of both sliding and abrasion drop even more sensitively with increasing debris content (Hallet, in preparation).

The theoretical notion that glaciers with relatively clean ice would be able to slide considerably faster than those with much basal debris, is in accord with reports from subglacial cavities, which generally indicate little debris and rapid sliding of basal ice (Theakstone 1967, Vivian 1975, Wold and Ostrem 1979, Anderson and others, in press) and recent bore-hole investigations, which reflect considerable debris at the bed and very slow sliding (Engelhardt and others, 1978). That relatively clean ice is generally observed in cavities is consistent with the present model; if the basal ice were rich in debris, it would not slide fast enough for ice-rock separation to occur.

A plausible model for the evolution of the ice-rock interface could entail initially clean ice that entrains debris as it slides over a rock bed. As the debris content increases beyond the transition concentration, the velocity would decrease, and would do so at a rate greater than the model predicts because of the effect of high debris content on effective viscosity of the ice. This reduction in sliding would continue as additional debris accumulates at the base due to net basal melting. However, because the drag imparted by debris on the glacier increases with the sliding rate, the impeding effect of debris diminishes as the glacier slows down. Hence, slow sliding would tend to persist until particles lodge against the bed. Over relatively smooth beds, rock fragments of a 1 sizes would start to lodge when sliding rates drop to rates equivalent to the rate at which basal ice melts due to geothermal heating. Fragment size does not enter in the lodgement process, because the pseudo-viscous forces causing particles to move along the bed and the effective contact forces that indirectly resist that motion both scale with the fragment diameter. Therefore, the ratio of these forces, which control the rate of movement of particles, is independent of size. Hence, all particles would tend to move at the same rate and size-sorting would not be expected to accompany the lodgement process.

Finally, it must be stressed that the debris content of basal ice may play an important role in controlling the motion of temperate glaciers by influencing the sliding rate. Considerably more data on and theoretical considerations of what controls the debris content of basal ice are necessary to better assess the effect of debris on glacier sliding. In addition, new theoretical studies are needed to model sliding and abrasion by temperate glaciers with much debris in the basal ice or by those underlain by till.

\section{ACKNOWLEDGEMENTS}

I am thankful to Charles Raymond, Joseph Walder, Derek Booth and Robert Anderson for critically reading and discussing various drafts of this manuscript. Through her careful review, Almut Iken motivated several important improvements of the manuscript. I am grateful for elucidating discussions of the abrasion process with Hans Röthlisberger, who kindly provided me with an extended unpubiished version of his paper on glacier erosion (1968). Special thanks are due to Robert Anderson who aided in the preliminary programming that laid the foundation for the model presented in this paper and to Mary Jo Pellerito for typing the final draft. The initial portion of this work was conducted at Stanford University with support provided by National Science Foundation Grant EAR77-13631. It was completed at the Quaternary Research Center, University of Washington, with support from National Science Foundation Grant EAR7919982. 


\section{REFERENCES}

Anderson R S, Hallet B, halder J, Aubry B F In press. Observations in a cavity beneath Grinnell Glacier. Earth Surface Processes

Boulton G S 1974 Processes and patterns of glacial erosion. (In Coates D R (ed) Glacial geomorphology. Binghamton, NY, State University of New York:41-87

Engelhardt H F, Harrison W D, Kamb W B 1978 Basal sliding and conditions of the glacier bed as revealed by bore-hole photography. Joumal of Glaciology 20(84) : 469-508

Gilbert GK 1906 Crescentic gouges on glaciated surfaces. Bulletin of the Geological Society of America 17(9): 303-316

Gilbert G K 1910 Harriman Alaska series, Vol.3. Glaciers and glaciation. Washington, DC, Smithsonian Institution

Goren S L 1970 The normal force exerted by creeping flow on a small sphere touching a plane. Joumal of Fluid Mechanics 41(3): $679-625$

Hallet B 1979 A theoretical model of glacial abrasion. Joumal of Glaciology 23(89): 39-50

Happel J, Brenner H 1965 Low Reynolas number hydrodynamics with special applications to particulate media. Englewood Cl iffs, $\mathrm{N} \mathrm{J}$, Prentice-Hall

L]iboutry L A 1979 Local friction laws for glaciers: a critical review and new openings. Journal of Glaciology 23(89): 67-95

McCall J G 1960 The flow characteristics of a cirque glacier and their effect on glacial structure and cirque formation. (In

Lewis W V (ed) Investigations on Nomegian cirque giaciers. London, Royal Geographical Society: $39-62$ (RGS Research Series 4)

Metcalf R C 1979 Energy dissipation during subglacial abrasion of Nisqually Glacier, Washington, U.S.A. Jourmal of Glaciology 23(89): 233-245

Morris EM 1979 The flow of ice, treated as a Newtonian viscous liquid, around a cylindrical obstacle near the bed of a glacier. Joumal of Glaciology 23(89): 117-129

Nye J F 1967 Theory of regelation. Phizosophical Magazine Ser 8 16(144): 1249-1266

Nye J F 1969 A calculation on the sliding of ice over a wavy surface using a Newtonian viscous approximation. Proceedings of the Royal Society of London, A 311(1506): 445-467

Nye J F 1970 Glacier sliding without cavitation in a linear viscous approximation. Proceedings of the Royal Society of London A 315(1522): $381-403$

O'Neil] ME 1968 A sphere in contact with a plane wall in a slow linear shear flow. Chemical Engineering Science 23(11): $1293-1298$

Röthlisberger H 1968 Erosive processes which are likely to accentuate or reduce the bottom relief of valley glaciers.

International Association of Scientific Hydrology Publication 79 (General Assembiy at Berm) : 87-97

Theakstone WH 1967 Basal sliding and movement near the margin of the glacier osterdalsisen, Norway. Joumal of Glaciology 6(48): 805-816

Vivian R A 1975 Les glaciers des Alpes Occidentales. Grenoble, Imprimerie Allier

Watts $P A$ Unpublished. Inclusions in ice. [PhD thesis, University of Bristol, 1974]
Wold B, estrem G 1979 Subglacial constructions and investigations at Bondhusbreen. Norway. Journat of Gtaciology 23(89): 363-379 